\title{
Metallic Additives Dispersed Polymer Composites for Irradiation Shielding- A Novel Critique
}

\author{
Vignesh Sreekandan Nair, Jothiraj Palaniappan, Winowlin Jappes JT
}

\begin{abstract}
Ionizing radiation finds its part in a wide spectrum of fields such as medicine, industry and research. These radiations in the form of alpha, beta, neutron particles, gamma and X-rays are very dangerous for not only humans but also for biotic and abiotic environments. The present article briefly works out the irradiation shielding ability of some potential composite materials to recognize the shielding tendency and enabling the same to find some promising applications in defense as well as nuclear research. The physics of irradiation decay and shielding is appraised in this critique. This review article studies about various materials employed for the attenuation of nuclear radiations and their response in terms of attenuation rates $\left(I / I_{0}\right)$ after exposure to the radiation. The study also focuses on the mechanical performance of the shielding materials meticulously for the application of dry storage of the spent fuel possessing a potential threat of radiation hazards. Moreover the evolution of composite materials in the structural applications is contemplated.
\end{abstract}

Keywords : Attenuation, Composite materials, Dry Storage, Irradiation shielding

\section{INTRODUCTION}

C omposite materials, the product of mixing or stacking two or more materials are a promising attraction to researchers in replacing conventional metallic materials. Although the problems of the product lies in its weak matrix constituting polymers that result in weak inter laminar shear strength, the best use of composite is because of its high specific strength, stiffness, fatigue behavior and density [1]. There is a profound need of composite materials for wide range of applications and various scientists across the globe are utilizing the available culture of materials ranging from natural fibers to carbon fibers in order to fabricate composites. These composite materials find its applications in aerospace, automotive, naval and civil industries[2]. Earlier in the previous century, scientists stepped their foot on to the research in composite materials and the last century being the pioneering phase of composite materials, the only acceptable

Revised Manuscript Received on December 30, 2019.

* Correspondence Author

Vignesh Sreekandan Nair*, Department of Mechanical Engineering, Kalasalingam, Academy of Research and Education, Krishnankoil, India, vignesh@klu.ac.in

Jothiraj Palaniappan, Department of Mechanical Engineering, Kalasalingam, Academy of Research and Education, Krishnankoil, India, jothiraj@klu.ac.in

Winowlin Jappes JT, Department of Mechanical Engineering, Kalasalingam, Academy of Research and Education, Krishnankoil, India, winowlin@klu.ac.in and readily available material was wood since it is naturally abundant in nature. Tailoring the wood and its component are done with ease which made the Wright Brothers to achieve the milestone in the aviation era. Later in 1930s the wood and fabric consumed in the pioneering phase was replaced by metal predominantly $\mathrm{Al}$ and that resulted in structural revolution. It can be noted that amidst of the last century the aero material used was composite material but the usage of it was restricted only to the manufacturing of secondary wing and tail components. Later the composite materials were used as a substitute for conventional aero structural material and the outcome of which was the development of some of the commercial airlines. Most of the common composite fibers are glass, carbon and organic and some of the dedicated applications were used with boron, silicon carbide and alumina those are commonly termed as ceramics and ceramic based fibers. Fiber glass was first used as an insulation material for thermal, electrical and acoustic applications. It is also used for wide variety of applications as it has good chemical resistance, resists water attacks on the other hand lacks in mechanical properties. Carbon fiber, irrespective of having wide potential properties such as resistance to high temperature, high strength, high stiffness to weight ratio, good corrosion resistance, is very expense and hence hinders its use in some of the commercial applications. The replacement of metals with composite laminates cuts down the weight reduction factor that results in upbringing the fuel efficiency, maneuverability and pay load capacity of the transportation vehicles [3]. The extreme environmental issues such as corrosion resistance and thermal expansion are established to be constructive upon the usage of some composite materials in such applications [4-5]. The application of high energy radiation is found in nuclear industries, medical, spacecraft, agriculture, defense and so on. It is mandatory to have proper protective measures from preventing exposure to radiation. Redundant exposure to high energy radiation is harmful always not only to living but also to non-living systems. Absorption of radiation energy or particles familiarly known as attenuation could hinder these hazards which can be achieved through the proper utilization of shielding materials[6-7].Traditionally lead, in the form of sheets, plates, foils, bricks and blocks, has been used owing to its high density, low cost and radiation shielding ability. Despite of these values, lack of mechanical strength, flexibility, chemical stability and toxicity limit the usage of the same in some sophisticated applications. 
Several researches suggested simple cost effective shielding material as concrete containing elements such as zeolite, barite, lead fly ash, bismuth oxide, basalt fiber, boron oxide, etc [8] as these materials provides excellent shielding to gamma ray and considered as effective building material.

Numerous researchers have reported the suitability of polymer composites in the field of radiation protection by considering a variety of polymer as matrix and fillers as reinforcements [9]. It should be also taken into account that energy needs of the globe is catered by adopting several measures internationally owing to the huge increase in economic growth as well as the growth in the population density [10-11] Around the globe, countries internationally promote the usage of nuclear power as a theme of sustainable development because of the absence of harmful by-products such as $\mathrm{CO} 2, \mathrm{CO}, \mathrm{NOx}$ and other harmful greenhouse gases.

Conversely the fuel used for nuclear power itself creates its own harmful wastes called Spent Nuclear Fuel which is paid major attention in managing the same to avoid serious threats to the environment. Several studies were done to manage the spent fuel waste and resulted in techniques such as wet storage, dry storage and re-usage [12]. However there are several factors to be considered in order to fabricate a shielding material for storing and disposing spent nuclear fuel and are not limited to good mechanical and corrosion resistance, aging resistance, impact resistance and so on[13]. The primary objective of this review is to critique the performance of some composite materials in order to find the applicability of the same in nuclear waste management. In addition, the inherent mechanical properties of the composite materials are also reviewed.

\section{Physics of Radiation Decay \& Interactions WITH MATTER}

In general, radiation turns out in two broad forms namely non- ionizing and ionizing radiation which is described in the Fig.1. The former results in the form of visible light, radar, laser light, ultra-violet rays, etc and causes approximately no damages to the tissues of a cell or to the material as a result of its low ionizing potential while the latter category of radiation carries enough energy within itself to alter the atoms in tissues and materials tops in electromagnetic spectrum [14] and $\alpha$ - decay, $\beta$ - decay, $\gamma$ - decay, neutron decay and X-rays are the major constituents of the same. Alpha $(\alpha)$ radiation whose particle being heavier, loses their energy upon hitting other atoms will not travel much far and can be shielded easily by common sheet of paper. Beta $(\beta)$ particles are smaller and travel faster when compared with $\alpha$ particle, can be shielded with a stack of plastics. On the other hand, gamma $(\gamma)$ radiation being an emission of energized photon rather being particle radiation, has neither mass nor charge and can proceed to a farther distance could be shielded with a block of heavier metal usually lead.

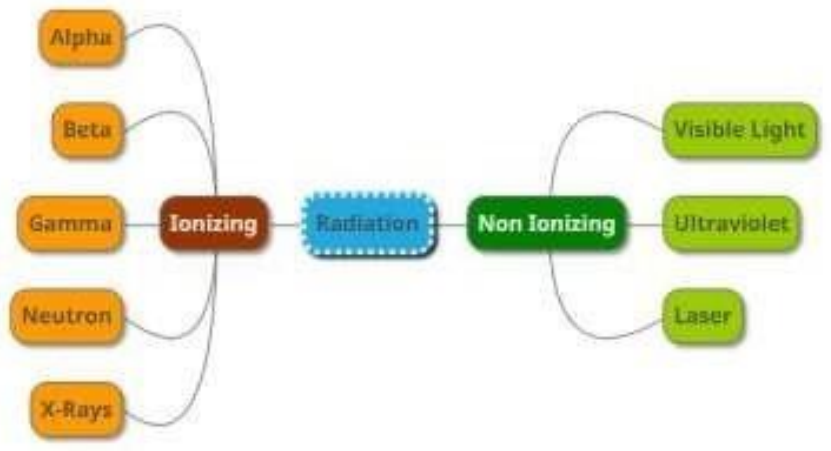

Fig.1. General Classification of Radiation

The neutron, a neutral particle within its nucleus becomes unstable as it crosses the boundary of a nucleus with a mean lifetime of 15 minutes. In disparity, lacking of charge has made the same to pass through the barriers which hinder all other charged particles [15]. The Figure 2 portrays the interaction of radiation particles and energized photons with other matters.

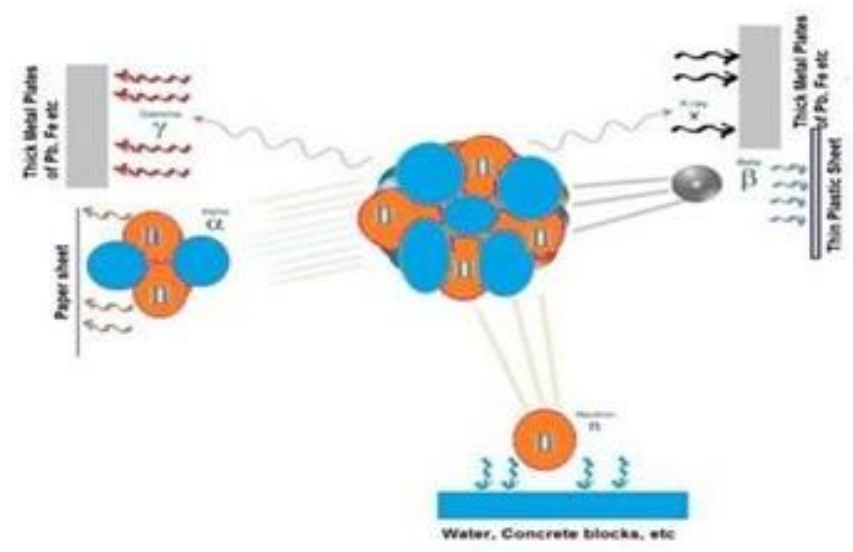

Fig. 2. Interaction of radiation particles and their possible shielding materials

It should be noted that researchers have shown great interest towards the shielding of neutron and gamma irradiation as they are the potential threats to the environment however the other decays were least bothered. Gamma irradiation rays being high energy photons identical to the photon responsible for the formation of visible light in the electromagnetic spectrum however possess energy 10000 times greater than that of the visible photons. Being a dreaded ionizing radiation follows three interaction mechanisms with matter namely photoelectric effect, Compton scattering and pair production. The low energy gamma rays interact with matter predominantly by photoelectric effect leading to the emission of photoelectrons when illuminated with light upon matter. However the probability of photoelectric absorption per unit mass is approximated by the below equation:

$$
\tau_{\text {photoelectric }}=K \frac{Z^{n}}{E^{3.5}}
$$

where $\mathrm{K}$ absorption constant, $\mathrm{Z}$ is the atomic number of the shielding material, $\mathrm{n}$ is the exponential that varies from 4 to 5 and $\mathrm{E}$ is the energy of the incident photon.

The above equation led to the conclusion that materials with high atomic number can be used for shielding gamma rays which is owing to $\mathrm{Z}$ being proportional to the absorption probability. 

responsible for the gamma rays follow Compton scattering phenomenon when interacted with matters.

Compton scattering is reported to be an inelastic scattering of photon by a charged particle predominantly an electron which deflects the incident gamma ray photon through an the reduction in the energy of the photon by transferring the same to the recoil electrons. The transferred energy may range from zero to a large fraction of energy of incident gamma ray. Since the Compton scattering is facilitated by the number of electrons, the probability of scattering per interaction with an atom increases linearly with atomic number $Z$. The phenomenon of conversion of energy directly into matter naturally is pair production. As far as interactions of gamma rays are concerned, at high energies this phenomenon is predominant in forming electron- positron pair when gamma rays are made to interact with matter.

\section{MATERIALS FOR IRRADIATION SHIELDING}

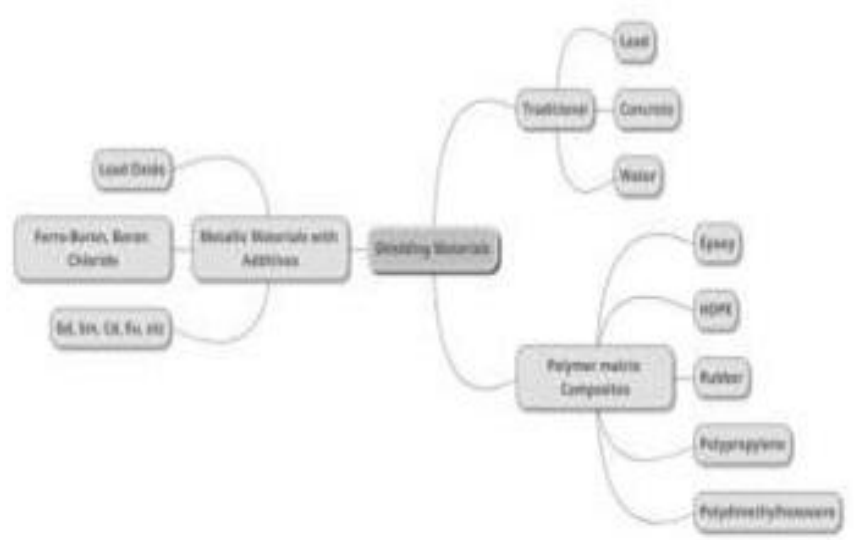

Fig.3. Wide range of shielding materials

The search for irradiation shielding materials has been considerably increased nowadays due to the steep increase in the demand of sophisticated equipments those using radiation and radioactive elements. A shielding material is considered effective for shielding neutron and gamma radiation only if the same is affluent of hydrogen and expected to be integrated with heavy metallic elements. It is because heavy elements give rise to inelastic scattering which moderates the fast neutrons. On the other hand presence of hydrogen in the polymer material will cool down the intermediate neutrons as an outcome of elastic scattering. It can be also noted that the heavy elements owing to the possession of great masses can absorb the secondary gamma rays and original gamma rays as well [16]. It is in general there are two phenomenon those induces damage when a shielding material is subjected to nuclear irradiation. One of such phenomenon is elastic scattering of neutrons and another being neutron absorption reaction. This work categorizes the wide range of materials spectrum into two; metallic shielding materials, metallic composites with polymer matrix and is depicted in Fig. 3. Recent researches are considering the fabrication and shielding performance of the latter since the fact that the constituents of a single composite can execute both the function of thermal absorption and moderation needed for efficient neutron shielding [17].
On the other hand photons of intermediate energy angle $\Theta$ corresponding to the original direction resulting in

\section{$\mathrm{B}_{4} \mathrm{C}$ as Additive}

Numerous studies reported metallic shielding aluminium composites reinforced with $\mathrm{B}_{4} \mathrm{C}$ has good modulus good melting point, high hardness, good tribological and impact properties and possess good chemical resistance [18]. Moreover these materials can absorb effectively the fast neutrons and thermal neutrons from a wide range of neutrons owing to the high neutron absorption cross-section of Boron thereby enabling the material as a neutron absorber for wet storage pools and dry storage casks as well [15]. Additionally the behavior of helium should be noted during the irradiation of $\mathrm{B}_{4} \mathrm{C}$ material which results in the development of helium cluster in the form of bubbles along the grain boundaries leading to end up with structural defects [21]. Numerous studies focused on the $\mathrm{B}_{4} \mathrm{C}$ content in the shielding material in order to confirm the suitability in the nuclear shielding applications. It was also reported by researchers that increase in $\mathrm{B}_{4} \mathrm{C}$ content tends to increase the neutron shielding ability of the material [22]. Moreover increase in the mass fraction of $\mathrm{B}_{4} \mathrm{C}$ was reported as an aid to increase the hardness of the material however that deteriorates the toughness of the material and therefore the fraction is restricted utmost to $30 \%$ in order to avoid degradation of mechanical properties [24]. Similarly hexagonal Boron nitrate could be also utilized for shielding from radiation because of its structure similar to that of graphite, a common material for moderators in nuclear reactors [23].

\section{Other Metallic Additives}

The use of other metallic materials as gadolinium, cadmium, europium, samarium and so on has been reported by some scientists as a result of the possession of good neutron absorption cross section by these materials $[25,26]$. Gadolinium tops the list by holding a very high neutron absorption cross- section though researches are very limited regarding its application for structural ability. On the other hand cadmium being a traditional poisonous shielding material is reported the inability to be used widely owing to the threat for the health concern of the human workforce mainly during the manufacturing processes [27].It is possible for a radiation source to emit both neutron and gamma radiations and hence it is not necessary to maintain different sources for the emission of these radiations. However based on the application under consideration radiation source is possible to be selected. It should be noted that there is no obstacle to dam the secondary gamma rays generated in a neutron field because of the following;

1. In-elastic scattering of fast neutrons with heavy nuclides,

\section{Neutron activation of structural materials [8]}

Tungsten provides excellent neutron shielding ability which is because of its thermal neutron cross-section[28-29]. 
It is well known that addition of metal additives with high atomic number will result in gamma ray attenuation which makes tungsten $(\mathrm{Z}=74)$ as a decent gamma ray shielding material as well. It is hence research works concluded the dual usage of tungsten as shielding material from both neutron and gamma radiations.

\section{Polymers as Shielding Material}

The fact which made interest among the scientists in order to consider polymers as an effective replacement for the traditional attenuating material is that the presence of hydrogen could act as a neutron moderator, which is obvious in most of the polymer chains. Epoxy falling under the hydrogenous materials was reported to be beneficial owing to its light weight property, low shrinkage resulting to dimensional stability, good mechanical strength and chemical resistance. Moreover aromatic ring in the backbone of polymer made the same durable over gamma and neutron irradiation. Some scientists have reported the enhancement of flame retardant property of polymers through proper addition of some organic additives [30-31].

Some characteristics properties like elasticity, high ignition temperature enabled Polydimethylsiloxane as a promising matrix material for shielding [23,32]. Moreover it is also reported in few studies about the spectacular improvement in the elastic modulus of the polymers with the addition of nanoparticles without trading off the fundamental benefits like low weight, transparency, easy processing and ductility [33,34]. Contradictorily, the piling up of nanoparticles resulted in polymer matrix with non uniformity in the dispersion of nanoparticles. However there are prominent processing techniques to overcome this such as functionalization, coating and ultrasonic processing [35-40]Several researchers had attempted to fabricate metallic composite shielding materials with the aid of hot extrusion, casting and infiltration [41]Certain studies on ceramic material like $\mathrm{SiC}$ reported its suitability for irradiation environment. The major attractions of using $\mathrm{SiC}$ for irradiation situation are its stability and low induced activation $[20,35]$

\section{AtTenuation STUdies}

It is well obvious that the objective of this critique is to study the attenuation studies of potential composite materials meant for irradiation shielding. With a view of above, searches revealed that some composite materials are good in irradiation damping. The characterization of radiation attenuation rates were done with thermal neutron diffractometer with various sources like ${ }^{241} \mathrm{Am},{ }^{133} \mathrm{Ba},{ }^{137} \mathrm{Cs}$, ${ }^{60} \mathrm{Co}$, etc. along with proportionate counter with $\mathrm{BF}_{3}, \mathrm{He}-3$, etc. kept at a safer suitable distance in order to avoid the scattered radiation reaching the detector.

The Fig. 4 depicts the basic characterization technique adopted for studying the attenuation behavior of an irradiation shielding material. Studies reveal that the reaction intended for capturing neutron in the most common additive material $\mathrm{B}_{4} \mathrm{C}$ is as follows [43]:

$$
10 \mathrm{~B}+\mathrm{n} \rightarrow 7 \mathrm{Li}+4 \mathrm{He}+\mathrm{Y}
$$

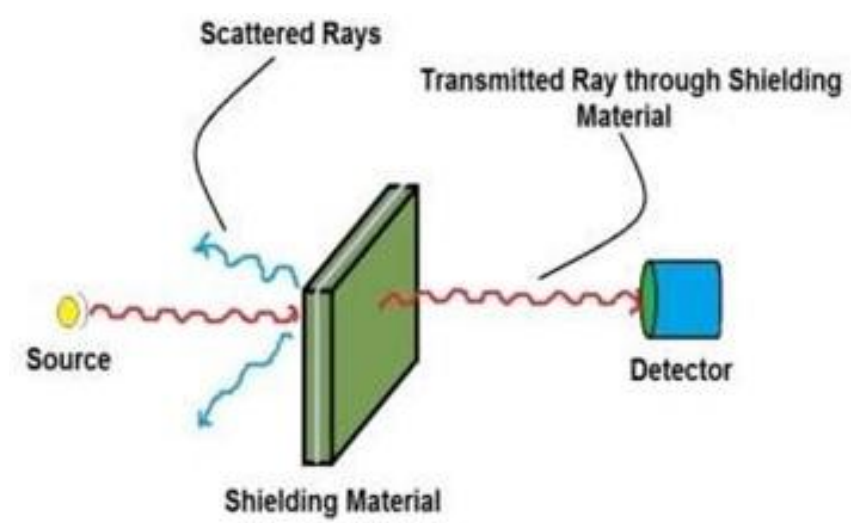

\section{Fig. 4. Schematic of the experimental setup to study irradiation properties}

it was proposed that $\mathrm{B}_{4} \mathrm{C}$ not only owing to more helium gripping, less helium rate but also for low bulging would be suitable as a reinforcement material. It is necessary for all researchers to estimate the neutron transmission intensity in order to gather information about the neutron attenuation rate $\mathrm{I} / \mathrm{I}_{0}$ which is expressed as $\mathrm{I}=\mathrm{I}_{0} \mathrm{e}^{-\sum \mathrm{td}}$, which uses the calculated data of intensity of thermal neutron transmission (I), intensity of incident thermal neutron $\left(\mathrm{I}_{0}\right)$, macroscopic transmission cross- section $\left(\sum \mathrm{t}\right)$ and the thickness of the neutron absorbing material (d). It is made public that attenuation rate is uncovered to be decreased with the increase in addition of $\mathrm{B}_{4} \mathrm{C}$ particularly with aluminium matrix composites [42]. However to the surprise, it is also reported with the further reduction in attenuation rate depending upon the fabrication process of shielding material. One such process is hot isostatic pressing which exposed the reduction in attenuation rate upon sintering the composite shielding material at $650^{\circ} \mathrm{C}$ with wealthy presence of $\mathrm{B}_{4} \mathrm{C}$.

On the other hand the phenomenal increase in $\mathrm{B}_{4} \mathrm{Cwas}$ reported to end with numerous porous sites in the material leading to less relative density of the material as well. Though it was found to have detrimental effects in the ability of the material to be sintered owing its deprived compatibility between the matrix and the reinforcement materials, but the tensile result was established to have an unique growth positively, conversely disclosed to be resulted with embrittlement of the material [44].However works have reported for the careful processing techniques for ensuring complete dispersion of $\mathrm{B}_{4} \mathrm{C}$ powders which ended up with zero agglomeration and aggregation of powder particles. One such method is ultrasonic sonication which results in complete mixture of powder particulates in the resin. The stability of the resin reported was not traded off upon employing Sonication process. It is also confirmed that with increasing thickness of the material with $\mathrm{B}_{4} \mathrm{C}$, initially the shielding effect increased gradually and then begun to detriment with enlarged thickness. It was reported to be attributed by the reduction in the ability of the material to absorb radiation which ended up with such a negative response. On the other hand the presence of bubbles, formation of pores and agglomeration affect the shielding performance of the composite conversely.

Numerous works have reported on the shielding 
property of $\mathrm{B}_{4} \mathrm{C}$ owing to its neutron absorption cross section. Reports suggest the usage of Ethylene propylene diene monomer (EPDM Rubber) with boron trioxide to shield effectively the neutron particles irradiation [45]. Observations by researchers on the increase in neutron attenuation coefficient with increase in $\mathrm{B}_{4} \mathrm{C}$ content with epoxy matrix subjected to low velocity ultrasonic stirring [46]. On contrast, the obvious reduction of shielding performance was reported by scientists beyond $10 \mathrm{~mm}$ thickness of the material comprising of $\mathrm{B}_{4} \mathrm{C}$ [47]. On the other hand results reveal composites filled with $\mathrm{B}_{4} \mathrm{C}$ and $\mathrm{Al}$ at a specific combination yielded good neutron shielding properties. Nevertheless similar trend was observed in the case of polypropelene as the shielding material. Upon irradiation, the material was stated the possession of excellent shielding whereas the ductility of the same shown a negative trend in its growth acknowledging the existence of low mechanical resistance when exposed to irradiation. It was ended with an observation of the fact that when a material was exposed to radiation, the Young's modulus of the same was improved which directly means the enhancement of the tensile strength of the material [48]. It was also observed that the similar trend was repeated as that of the single polypropelene material even if altering the melt indexing flow of polypropelene and stacking, and stacking two polypropelene composites of different melt index flow, however improvement in shielding ability of the material in the above case was reported due to the increase in the thickness of the material [48]. It was also recommended that adding $\mathrm{PbO}$ to the polymer matrix shielding material exhibited appreciable attenuation and shielding properties.

Moreover the growth in the shielding properties was reported with incremental trend upon adding other heavy metals as minor additions with $\mathrm{PbO}$ [48]. Researchers earlier revealed the limitations of using carbon fiber with polymer matrix owing to low bonding ability and low surface energy $[16,22]$. On the other hand subjecting the material to suitable surface treatment techniques could overcome the above limitations and reported to develop irradiation shielding ability of the material. Rare earth metals are widely used nowadays to prepare materials with luminescence property. Several rare earth metals are employed for developing shielding materials but studies are very much limited to Gadolinium which finds a promising role owing to its high thermal neutron cross-section area. Researchers suggest the usage of Gadolinum Oxide $\left(\mathrm{Gd}_{2} \mathrm{O}_{3}\right)$ with high density polyethelene polymer for irradiation shielding applications. Moreover adopting a suitable fabrication techniques were reported to yield superior shielding properties as well as mechanical properties by several researchers. Hot rolling technique adopted for fabricating $\mathrm{Gd}$ and $\mathrm{B}_{4} \mathrm{C}$ based Aluminum composite is suggested to have better shielding properties. However it is reported by scientists that particle size plays a major role in enhancing the shielding and mechanical properties. Reports suggest the reduction in particle size of gadolinium to the nanoscale had greatly influenced the grain boundary enhancement thereby augmenting neutron irradiation shielding $[19,49]$.

\section{CONCLUSION}

Composite materials have now become a potential replacement for many of the structural materials, aerospace and transportation materials. A wide range of potential composites were contemplated for their secure application in the field of irradiation shielding. Since the area of research is budding and the solid investigations on the performance of composite materials for irradiation shielding is limited only to shielding attenuation studies. The topic of interest of the researchers greatly lies on designing and fabricating the absorption material with great thickness. However functionally graded composite materials were less reviewed owing to limited availability. More investigators shown their affinity towards the interaction mechanism of radioactive rays when subjected to irradiation, still incorporation of mechanical studies is still greatly found to be scarce which can be overcome by performing some mechanical stability investigation on the defending material for irradiation.

The works suggested by scientists reveal the suitability of materials of high atomic number which leads to good photoelectric absorption at low energies and positive Compton shift at intermediate energies. On the other hand the same possess greater likeness towards forming electron-positron pair at extremely high energies. Neutron particle radiation, being neutral however interacts with matter when subjected through scattering, absorption and transfer can be attenuated by atoms like hydrogen and oxygen, yet the woks on oxygen rich materials for shielding is inadequate.

On the other hand hydrogen rich materials like polymers based on epoxy, HDPE, Rubber, EPDM Rubber, Polypropylene were extensively studied by authors and reported in numerous scientific reports. Careful methods of fabrication technique are reported to be followed to ensure complete dispersion in the case when some additives of high atomic number are used. Very few investigators have suggested the employment of ultrasonic dispersion/ mixing technique so as to evade aggregation and agglomeration of particles. Few have reported the use of sonication in dispersing the additives without thermally degrading the same.

However the mechanical properties of some composite with $\mathrm{B}_{4} \mathrm{C}$ and $\mathrm{Gd}_{2} \mathrm{O}_{3}$ were reported to be enhanced owing to gain boundary strengthening mechanism. On the other hand the ductility of the composite was reported with the detrimental trend with the increase in composition of additives. Similarly care was given by the researchers in fabrication techniques of shielding materials for irradiation. The additive like $\mathrm{PbO}$ was reported to have better shielding attenuation when mixed in minute weight. Moreover trends on consumption of carbon fibers as fillers and Hexagonal boron nitrate as additives are paving promising way in attenuating irradiation photons. However studies on the production of irradiation guarding material must be entertained other than the conventional powder metallurgical process, molding by compression and usual hand lay-up technique in order to attract research. 


\section{Metallic Additives Dispersed Polymer Composites for Irradiation Shielding- A Novel Critique}

\section{REFERENCES}

1. Hatwig G, Knaak S, Fibre-Epoxy Composites at Low Temperatures,

2. Cryogenics 24(11) (1984), 639-647

3. C. Soutis, Carbon fiber reinforced plastics in aircraft construction, Mater. Sci. Eng. A 412 (1) (2005) 171-176.

4. K. Friedrich, A.A. Almajid, Manufacturing aspects of advanced polymer composites for automotive applications, Appl. Compos. Mater. 20 (2) (2013) 107-128.

5. R.M. Jones, Mechanics of Composite Materials, CRC press, 1998.

6. M.F. Ashby, Materials Selection in Mechanical Design, ButterworthHeinemann Press, 2005.

7. P. Kim, A comparative study of the mechanical performance and cost of metal, FRP, and hybrid beams, Appl. Compos. Mater. 5 (3) (1998) 175-187.

8. Manalo, T. Aravinthan, A. Fam, B. Benmokrane, State-of-the-art review on FRP sandwich systems for lightweight civil infrastructure, J. Compos. Constr. (2016)

9. R. Adeli, S. P. Shirmardi, and S. J. Ahmadi, "Neutron irradiation tests on B4C/epoxy composite for neutron shielding application and the parameters assay," Radiat. Phys. Chem., vol. 127, pp. 140-146, Oct. 2016.

10. M. R. Ambika et al., "Preparation and characterisation of IsophthalicBi2O3 polymer composite gamma radiation shields," Radiat. Phys. Chem., vol. 130, pp. 351-358, Jan. 2017.

11. H. S. Chen, W. X. Wang, Y. L. Li, P. Zhang, H. H. Nie, and Q. C. Wu, "The design, microstructure and tensile properties of B4C particulate

12. reinforced 6061 Al neutron absorber composites," J. Alloys Compd., vol. 632, pp. 23-29, May 2015.

13. J. Dumazert et al., "Advancements in Gd-based neutron detection: $\gamma-\gamma$ coincidence approach," Nuclear Instruments and Methods in Physics Research, Section A: Accelerators, Spectrometers, Detectors and Associated Equipment, Elsevier B.V., 2018.

14. B. R. Evans, J. Lian, and W. Ji, "Evaluation of shielding performance for newly developed composite materials," Ann. Nucl. Energy, vol. 116, pp. 1-9, Jun. 2018.

15. X. Fu, X. Tang, Y. Hu, H. Li, and J. Tao, "Effect of different lay-ups on the microstructure, mechanical properties and neutron transmission of neutron shielding fibre metal laminates," J. Nucl. Mater., vol. 475, pp. 227-236, Jul. 2016.

16. D. Gosset, P. Herter, and V. Motte, "Evaluation of damage in neutron irradiated boron carbide," Nucl. Instruments Methods Phys. Res. Sect. B Beam Interact. with Mater. Atoms, vol. 434, pp. 66-72, Nov. 2018.

17. M. R. Gual, A. Z. Mesquita, and C. Pereira, "Evaluation of an alternative shielding materials for F-127 transport package," Radiat. Phys. Chem., vol. 144, pp. 29-33, Mar. 2018.

18. Y. Huang, W. Zhang, L. Liang, J. Xu, and Z. Chen, “A,, Sandwich“ type of neutron shielding composite filled with boron carbide reinforced by carbon fiber," Chem. Eng. J., vol. 220, pp. 143-150, Mar. 2013.

19. B. K. Jang, J. C. Lee, J. H. Kim, and C. W. Chung, "Enhancement of thermal neutron shielding of cement mortar by using borosilicate glass powder," Appl. Radiat. Isot., vol. 123, pp. 1-5, May 2017.

20. M. A. Kiani, S. J. Ahmadi, M. Outokesh, R. Adeli, and A. Mohammadi, "Preparation and characteristics of epoxy/clay/B4C nanocomposite at high concentration of boron carbide for neutron shielding application," Radiat. Phys. Chem., vol. 141, pp. 223-228,

21. Dec. 2017

22. L. T. Jiang, Z. G. Xu, Y. K. Fei, Q. Zhang, J. Qiao, and G. H. Wu, "The design of novel neutron shielding $(\mathrm{Gd}+\mathrm{B} 4 \mathrm{C}) / 6061 \mathrm{Al}$ composites and its properties after hot rolling," Compos. Part B Eng., vol. 168, pp. 183-194, Jul. 2019

23. Y. Katoh et al., "Continuous $\mathrm{SiC}$ fiber, CVI SiC matrix composites for nuclear applications: Properties and irradiation effects," J. Nucl. Mater., vol. 448, no. 1-3, pp. 448-476, 2014.

24. R. Li, Y. Gu, Z. Yang, M. Li, Y. Hou, and Z. Zhang, "Gamma ray shielding property, shielding mechanism and predicting model of continuous basalt fiber reinforced polymer matrix composite containing functional filler," Mater. Des., vol. 124, pp. 121-130, Jun. 2017.

25. M. E. Mahmoud, A. M. El-Khatib, M. S. Badawi, A. R. Rashad, R. M. El-Sharkawy, and A. A. Thabet, "Recycled high-density polyethylene plastics added with lead oxide nanoparticles as sustainable radiation shielding materials,” J. Clean. Prod., vol. 176, pp. 276-287, Mar. 2018.

26. T. Özdemir and S. N. Y1lmaz, "Mixed radiation shielding via 3-layered polydimethylsiloxane rubber composite containing hexagonal boron nitride, boron (III) oxide, bismuth (III) oxide for each layer," Radiat. Phys. Chem., vol. 152, pp. 17-22, Nov. 2018.

27. X. Pang, Y. Xian, W. Wang, and P. Zhang, "Tensile properties and strengthening effects of $6061 \mathrm{Al} / 12 \mathrm{wt} \% \mathrm{~B} 4 \mathrm{C}$ composites reinforced with

nano-A12O3 particles,” J. Alloys Compd., vol. 768, pp. 476-484, Nov. 2018.

28. J. J. Park, S. M. Hong, M. K. Lee, C. K. Rhee, and W. H. Rhee, "Enhancement in the microstructure and neutron shielding efficiency of sandwich type of 6061Al-B4C composite material via hot isostatic pressing," Nucl. Eng. Des., vol. 282, pp. 1-7, 2015.

29. M. J. Saif, M. Naveed, H. M. Asif, and R. Akhtar, "Irradiation applications for polymer nano-composites: A state-of-the-art review," J. Ind. Eng. Chem., vol. 60, pp. 218-236, Apr. 2018.

30. D. Sarıyer, R. Küçer, and N. Küçer, "Neutron Shielding Properties of Concretes Containing Boron Carbide and Ferro - Boron," Procedia Soc. Behav. Sci., vol. 195, pp. 1752-1756, Jul. 2015.

31. I. Solodkyi et al., "Addition of carbon fibers into B4C infiltrated with molten silicon," Ceram. Int., vol. 45, no. 1, pp. 168-174, Jan. 2019.

32. Z. Soltani, A. Beigzadeh, F. Ziaie, and E. Asadi, "Effect of particle size and percentages of Boron carbide on the thermal neutron radiation shielding properties of HDPE/B4C composite: Experimental and simulation studies," Radiat. Phys. Chem., vol. 127, pp. 182-187, Oct 2016.

33. Z. G. Xu, L. T. Jiang, Q. Zhang, J. Qiao, D. Gong, and G. H. Wu, "The design of a novel neutron shielding B4C/Al composite containing Gd," Mater. Des., vol. 111, pp. 375-381, Dec. 2016.

34. P. Zhang, Y. Li, W. Wang, Z. Gao, and B. Wang, "The design, fabrication and properties of $\mathrm{B} 4 \mathrm{C} / \mathrm{Al}$ neutron absorbers," J. Nucl. Mater., vol. 437, no. 1-3, pp. 350-358, 2013.

35. Akkurt, I., El-Khayatt, A.M., The effect of barite proportion on neutron and gamma ray shielding. Ann. Nucl. Energy 51, (2013) 5-9.

36. Akkurt, I., Akyıldırım, H., Mavi, B., Kilincarslan, S., Basyigit, C., Radiation shielding of concrete containing zeolite. Radiat. Meas. 45, (2010) 827-830.

37. Akkurt, I., Akyildirim, H., Mavi, B., Kilincarslan, S., Basyigit, C., Gamma-ray shielding properties of concrete including barite at different energies. Prog. Nucl. Energy 52, (2010), 620-623.

38. K.M. Shorowordi, T. Laoui, A. Haseeb, J.P. Celis, L. Froyen, Microstructure and interface characteristics of $\mathrm{B} 4 \mathrm{C}, \mathrm{SiC}$ and $\mathrm{Al} 2 \mathrm{O} 3$ reinforced $\mathrm{Al}$ matrix composites: a comparative study, J. Mater. Process. Technol. 142 (3) (2003) 738-743.

39. A. Abdollahi, A. Alizadeh, H.R. Baharvandi, Dry sliding tribological behavior and mechanical properties of Al2024-5 wt.\%B4C nanocomposite produced by mechanical milling and hot extrusion, Mater. Des. 55 (2014) 471-481.

40. Y. Dou, Y. Liu, Y. Liu, Z. Xiong, Q. Xia, Friction and wear behaviors of B4C/6061Al composite, Mater. Des. 60 (2014) 669-677.

41. K. Kalaiselvan, N. Murugan, S. Parameswaran, Production and characterization of AA6061-B4C stir cast composite, Mater. Des. 32 (7) (2011) 4004-4009.

42. Yiping Huang, Lu Liang, Jiao Xu, Weijiang, Zhang, The design study of a new nuclear protection material, Nuclear Engineering and Design, 248 (2012), 22-27

43. Z. Zhou, G. Wu, L. Jiang, R. Li, Z. Xu, Analysis of morphology and microstructure of $\mathrm{B} 4 \mathrm{C} / 2024 \mathrm{Al}$ composites after $7.62 \mathrm{~mm}$ ballistic impact, Mater. Des. 63 (2014) 658-663.

44. H.S. Chen, W.X. Wang, Y.L. Li, J. Zhou, H.H. Nie, Q.C.Wu, The design, microstructure and mechanical properties of $\mathrm{B} 4 \mathrm{C} / 6061 \mathrm{Al}$ neutron absorber composites fabricated by SPS, Mater. Des. 94 (2016) 360-367.

45. H.S. Chen,W.X. Wang, Y.L. Li, P. Zhang, H.H. Nie, Q.C.Wu, The design,microstructure and tensile properties of $\mathrm{B} 4 \mathrm{C}$ particulate reinforced $6061 \mathrm{Al}$ neutron absorber composites, J. Alloys Compd. 632 (2015) 23-29.

46. P. Zhang, Y. Li, W. Wang, Z. Gao, B. Wang, The design, fabrication and properties of B4C/Al neutron absorbers, J. Nucl. Mater. 437 (1-3) (2013) 350-358.

47. B. Buyuk, A.B. Tugrul, M. Cengiz, O. Yucel, G. Goller, F.C. Sahin, Radiation shielding properties of spark plasma sintered boron carbidealuminium composites, Acta Phys. Pol. A 128 (2B) (2015) B132- B134

48. J.-J. Park, S.-M. Hong, M.-K. Lee, C.-K. Rhee,W.-H. Rhee, Enhancement in the microstructure and neutron shielding efficiency of sandwich type of 6061Al-B4C composite material via hot isostatic pressing, Nucl. Eng. Des. 282 (2015) 1-7.

49. A.V. Pozdniakov, V.S. Zolotorevskiy, R.Y. Barkov, A. Lotfy, A.I Bazlov, Microstructure and material characterization of 6063/B4C and $1545 \mathrm{~K} / \mathrm{B} 4 \mathrm{C}$ composites produced by two stir casting techniques for nuclear applications, J. Alloys Compd. 664 (2016) 317-320. 


\section{AUTHORS PROFILE}

Vignesh Sreekandan Nair has graduated in the field of Mechanical Engineering from Anna University in 2013 He completed his post-graduation in Manufacturing Engineering from Anna University in 2016. He has published one paper in peer reviewed journal. His research area of interests are casting of non-ferrous alloys, development of polymer composites and mechanical behavior of materials. Presently he is working with Kalasalingam Academy of Research and Education as an Assistant professor in the department of Mechanical Engineering.

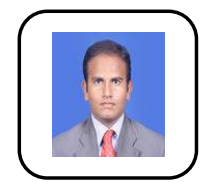

Jothiraj Palaniappanhas completed his bachelor's degree in the department of Mechanical Engineering under Anna University with First rank and gold medal, proceeded with the degree of masters under the Manufacturing Engineering with First Rank and Gold medal. He is being nominated and selected as the Mentor for change under the NITI-Ayog, Govt. of India for AIM. Has published two papers in peer reviewed journals. Active member in the IAEng. Research interest being inclined towards the advanced materials as shape memory alloys and phase changing materials

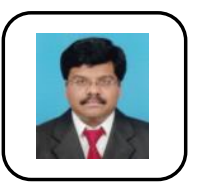

Winowlin Jappes J $\mathbf{T}$ graduated in 1997 from Manonmaniam Sunderanar University, India in Mechanical Engineering. In 1999, he has completed his masters in Production Engineering from Annamalai University. He completed his Ph.D degree in 2004 in the area of Composite Deposition at Indian Institute of Technology Madras, Chennai. He has completed three DST funded research projects and published more than 125 research articles which includes 65 International Journal papers. Currently, he is working as Senior Professor in Kalasalingam University, India. His research interests includes high performance composite materials, machining of hard materials, optimization techniques, etc. At present, he is working as Professor and Dean, School of Automotive and Mechanical Engineering, Kalasalingam Academy of Research and Education, India. 